\title{
Out-of-place: the lack of engagement with parent networks of caregiving fathers of young children
}

\author{
Rachel Brooks and Paul Hodkinson, University of Surrey
}

\section{Abstract}

This article explores the daytime social interactions of fathers who have assumed primary or equal responsibility for the care of their young children. For most such fathers in our sample, contact with other parents during their day-to-day care was minimal. Many rationalised their isolation as a personal preference rooted in their own 'introverted' nature. Nevertheless, such individualised narratives underplay how various systemic factors worked against their integration into parent networks, including: feeling 'out-of-place' in many daytime public spaces; a fear of being judged because of their gender; and the difficulty of meeting other fathers with responsibility for day-to-day care. The operation of these factors provides evidence of the enduring nature of gender differences with respect to early years parenting and, in particular, of the gendering of daytime public parenting spaces - something that may represent a barrier to the extent and longevity of fathers' caregiving roles.

Keywords: fathering, parenting, gender, public space 


\section{Out-of-place: the lack of engagement with parent networks of caregiving fathers of young children}

\section{Background}

Over recent years, the concept of 'involved fathering' has gained widespread cultural acceptance - across many different national contexts (Chelsey, 2011; Dermott, 2009). Indeed, there is now a reasonable consensus amongst both policymakers and researchers that when fathers take on substantial caring responsibilities, both family life and the well-being of children can be enhanced, while such practices also help to address gender gaps in earnings and status (Chesley 2011). However, although there is evidence that fathers are more involved in care-giving than their own fathers, mothers still do significantly more and this is particularly pronounced in early years parenting (Parke, 2013). Dermott (2009), for example, argues that contemporary fathering tends to valorise emotional connection and intimacy rather than sharing equally everyday childcare 'work', while Miller (2011) shows that, while men may aim to play an equal role, such ambitions are rarely realised - not least because of the pull of paid employment. Fathers, it is argued, tend to have fewer constraints on their choices than mothers (Dermott, 2009) and 'can move more easily - and less guiltily - in and out of paid work and the home' (Miller 2011, p.154).

Against this context, the research that forms the basis for this article examined the experiences of 24 British men who, unlike the majority of their peers, had taken up at least an equal share of caregiving responsibility for a young child. While there are now a number of studies focussed on dads who are primary caregivers (e.g. Brandth and Kvande, 2018; 
Doucet, 2006a; Merla 2008), our work takes a somewhat broader angle, by exploring the experiences and practices of fathers who are primary carers alongside those who are sharing parenting responsibilities equally with their partners. Our UK focus is also important, tying in with other emerging work on caregiving fathers in the country (Banister and Kerrane, 2018; Norman et al., 2018; O’Brien and Twamley, 2017), amidst a body of previous research that has largely been conducted in other national contexts, including Norway (Brandth and Kvande, 2018), Belgium (Merla, 2008), Canada (Doucet, 2006a; Ranson, 2010) and the US (Chelsey, 2011; Solomon 2017).

Our particular concern in this article is with such fathers' engagement with networks of other parents during the days they are in sole charge of their children. Levels of participation in such networks have potential implications for the wellbeing of such fathers and the activities in which their children participate, as well as for the conclusions we may draw about how far shared or primary parenting extends for such men. Informed by findings in existing research that indicate caregiving fathers can find themselves marginalised within such networks, we explore here i) to what extent our UK primary and equal caregiver fathers were isolated or marginalised from parent networks and, in particular, ii) what factors might explain this. Through addressing such questions we contribute to understandings of the continued operation of gender in relation to care-centred fathering and, more specifically, the way this intersects with the gendering of public daytime parenting spaces.

\section{Fathers and parenting networks}

Interactions with other parents have long comprised a core part of the daily routine of many mothers who are primary caregivers for young children (Doucet 2006). Attendance at 
organised parent and infant events, children's activities and a range of more informal gatherings in parks, shopping centres, cafes and in one another's houses forms a key element of what Doucet (2006a) refers to as 'community responsibility' for the upbringing of children, whilst also offering crucial sources of company and support, not least in the first year of babies' lives (Mulcahy et al., 2010). Indeed, such activities and connections, argues Doucet, can form a key facet of contemporary mothering (ibid.).

Research has suggested, however, that fathers who care for children alone on weekdays may engage less with such spaces and networks - with potential implications for the extent of the parental responsibilities they are taking on, their own wellbeing and comfort within their role, and the prospects of longer-term commitment to it. Existing research in Canada by Doucet (2006b) and Ranson (2010), in Belgium by Merla (2008) and the US by Soloman (2017) indicates that many such fathers have less contact with other parents than do mothers and that, as a consequence, they sometimes can lead rather solitary week-day lives with little adult contact (also see Medved 2016). Recent UK research on fathers on parental leave has indicated a similarly isolating experience (O'Brien and Twamley, 2017). Meanwhile, fathers' experiences of interactions within parent networks, even among those most actively engaged, tended to be characterised by awkwardness. In Ranson's study, a significant minority of fathers did make use of baby groups - something revealingly described by one as 'breaking cover' - but they typically commented on the 'gender barrier' within such environments and awkwardness of being the only man. Moreover, Merla (2008) describes how stay-at-home fathers could feel ostracised and judged within female parenting spaces. Similarly, although there was diversity among her primary caregiver fathers, Doucet argues that community engagement overall was considerably lower than for mothers, and frequently characterised by gendered awkwardness: 
... every stay-at-home father described an uncomfortable or downright painful experience in playgroups or, more generally, in the parenting community. Some fathers glanced into the windows of the culture and quickly made the decision to avoid mother-dominated settings; they cited lack of time, fears that their child would catch a cold or flu, or the kids' schedules. Sometimes these reasons seemed justified. Other times it was clear that they are just avoiding one of the most female-dominated areas of early parenthood. (p.139)

As well as identifying a substantial minority of men in her study who had successfully integrated into parent networks, however (something also true of Ranson's study), Doucet (2006a) also signals a broadly optimistic note about the future, suggesting that men are gradually finding it easier to integrate with groups of mothers. Moreover, recent research on US stay-at-home fathers by Soloman (2017) identifies a mixture of positive and more marginalising experiences in daytime parenting spaces.

Although description of caregiving fathers' difficulties engaging with parenting networks is extensive in these studies, there may be room for further development with respect to the explanation for such experiences. Doucet (2006a), who does explore such questions in depth, focuses her conceptual explanation on the different beliefs and practices men and women have about friendship. While empirically recognising the ostracism fathers sometimes face in spaces dominated by mothers (also see Doucet 2006b), the bulk of her conceptual argument on the point relates to masculine inhibitions regarding gender and friendships. She writes: 'The majority of fathers in my study comment that the friendship and connection necessitated by the daily work of care are often beyond what they have known from their own 
experiences, having grown up as boys, engaging in traditional male friendships or believing that men and women simply form friendships differently' (p.151). Moreover, she argues that the enduring dominance of hegemonic masculinity makes it difficult for stay-at-home dads to make friends with one another - because of the assumption that talking about child-rearing is not an appropriate topic of conversation - or with mothers - because of concerns that such friendships will be viewed with suspicion by spouses and others. While we do not doubt the importance of such gendered inhibitions, there remains, we would suggest, more that can be worked through with respect to other factors at play, including how the direct barriers that fathers may face when they do seek to engage may be understood through reference to the transgression of dominant masculinities and the gendering of space.

In the discussion that follows, we extend existing work through examining the experiences of a small sample of UK caregiving fathers and, specifically, those of equal- as well as primarycaregivers. We begin by exploring the extent to which these fathers were marginalised from networks of parents, comparing this with extant scholarship. We then move onto an analysis of the factors that may affect paternal (lack of) participation in such networks. We first consider gendered differences between mothers and fathers with respect to levels of motivation or pressure to go out and engage with other parents, connecting this to Doucet's (2006a) discussions of friendship and to notions of intensive motherhood (Hays, 1998). We go on, however, to focus most of our discussion on how the primary or equal caregiver fathers in our sample did experience daytime parenting spaces when they spent time in them, and the ways this had affected their future engagement. Here, we extend existing understandings by drawing on conceptual understandings of the gendering of public space. 


\section{Methods}

The article draws upon individual, in-depth (single) interviews that were conducted between June and September 2016 with 24 fathers who had primary responsibility for looking after one or more young children (aged three or under) or who were sharing such responsibility equally with their partner. For the purpose of the study, we defined equal and primary caregiver on the basis of the amount of participants' self-reported level of everyday involvement in caregiving tasks as compared to their partner or spouse. We were particularly interested in fathers whose caring responsibilities connected to changes to work (whether voluntary or enforced), such as periods of extended parental leave, adjusted hours, working flexibly or part-time, changing job or becoming unemployed, and all of these are represented in our sample. Eligibility was determined via an information sheet and a set of screening questions. All respondents were in heterosexual relationships and lived in the same household as their children and partner at the time of the interview. We targeted fathers of young children on the grounds that it is often at this stage of a child's life that traditionally-gendered patterns of childcare become established and are at their most acute. Our approach to recruiting fathers consisted of placing advertisements in a variety of locations close to the university where we were based, including GPs' surgeries, children's centres and nurseries. We also advertised the project on online parenting websites and social media. In addition, two respondents were identified through snowball sampling from existing participants.

We achieved considerable variety in terms of the fathers' caring arrangements: overall 14 were sharing care-giving (more-or-less) equally with their partner, eight were the primary caregiver in their family (whether full- or part-time) and two were on Shared Parental Leave. Primary caregivers included stay-at-home dads but also fathers who were in paid employment 
but took main responsibility for the care of their children (in such cases their partner was typically employed for more hours than they were). They did considerably more than their partners with respect to tasks such as dressing and feeding their children, playing with them, taking them to and from any external childcare, and organising their day-to-day activities. In contrast, those categorised as 'equal care-sharers' tended to share such tasks on a more-orless equal basis with their partners, and also had similar patterns of employment (e.g. both working on a part-time basis). The length of time that such arrangements had been in place varied between families. Nevertheless, many viewed it as a relatively permanent arrangement, at least while their children were young. The families had arrived at this arrangement through a variety of different routes - and often for pragmatic rather than ideological reasons. The sample is less diverse, however, with respect to ethnicity and social class: all of the men were white, and most were working in professional occupations or had done so in the recent past. It is possible, therefore, that our findings are generalizable only to other white, middle class groups.

Half the interviews were carried out in person (in public spaces, respondents' homes or our university), and the other half by Skype. Interviews were carried out by the article's authors. Aside from occasional technical issues, we noticed few differences between face-to-face and Skype interviews in terms of participants' comfort and willingness to talk openly. The interviews lasted between 60 and 90 minutes and covered the following topics: how care responsibilities were divided up within the family and the factors that led to this; how the division of care was working out in practice; the impact of the caring arrangements on work and career; and the level and nature of contact with other parents, education/health-care professionals and parent support organisations. All interviews were audio-recorded and fully transcribed. Our analytical approach involved both deductive and inductive approaches. We 
coded the transcripts thematically using codes derived from the literature (for example, relating to some of the points discussed above), but also added numerous codes of our own to record ideas emerging from the data and not captured in previous research. A software package for qualitative analysis was used and codes were applied systematically and rigorously. Patterns across the coded material were identified and explanations developed. Pseudonyms have been given to all our interviewees to preserve their anonymity.

\section{'Just the two of us': fathers' lack of contact with other parents}

Nearly all the fathers described their childcare arrangements in broadly positive terms, identifying a range of advantages to them, their partner and/or their children. These included: supporting their partner in advancing her career; developing a closer bond between them and their child/children; and reducing the need for childcare. Nevertheless, when it came to social interactions with other parents, most respondents described a substantial difference between them and their partner. While there were one or two exceptions (who did not indicate a substantial difference between their level of contact with parent networks and that of their partner), most noted that they made much less use of playgroups and other structured group activities than did their partner when she was in sole charge of the children. Jason ${ }^{\mathrm{i}}$ (primary caregiver), for example, commented, 'My partner was very good at it [taking part in organised activities such as playgroups], I'm not so much.' Similarly, a large majority of the fathers reported that they had fewer social interactions in general with other parents than did their partner or other mothers. These comments are typical: 
My wife, my partner, she's often going to see other mothers like to, in town, to have a walk or have a coffee or... But myself, yeah, it's more, it's.... Yeah, no I don't, I don't meet people on those Fridays, it's just my son and I. (Thomas - equal caregiver)

I definitely do less group socialising than the stay at home mums that we know .... A lot of them use the group socialising as part of their day-to-day structure, so they always meet up with a group of their friends and kids on a day to day basis, whereas I don't. (Timothy - primary caregiver)

As a consequence, many of our interviewees (17 of the 24$)$ were spending the majority of the days when they were in sole charge of their children either at home by themselves or visiting local cafes or parks - again by themselves. John's (equal caregiver) description of his day is typical: 'Mostly on my own together, on our own together, yeah, the two of us'.

Of course, such experiences of relative social isolation during the day are experienced by some mothers, too. Indeed, Miller (2005) notes that this is particularly the case for some very new mothers, who limit their presence in public space because of feelings of insecurity in their 'mother' identity. Nevertheless, our data suggest that there is also an important gender dimension to such experiences in the case of these men, evident in both the comparisons they drew between themselves and their partners, and some of the specific experiences they described. We explore this in more detail below, as we consider some of the reasons for the fathers' lack of social interaction, beginning with the explanations proffered by the fathers themselves. 


\section{Explaining the relative absence of parental social interaction}

\section{$\underline{\text { Self-ascribed introversion }}$}

In their own explanations of their lack of contact with other parents, the fathers focussed primarily on their own personal characteristics or preferences. Indeed, a marked feature of the fathers' narratives was the frequency with which the words 'introvert' and/or 'unsociable' were used. Over half the sample used this kind of language (15 of the 24 fathers); the following quotation is typical:

I suppose partly I am, I'm something of an introvert, so I'm perfectly [happy on] ... my own, at my own time, you know this is seven weeks where there's relatively few people talking at me, which is nice. (Chris - parental leave)

It is, of course, possible that introverted individuals may have been over-represented in our sample. Alternatively, this language could also be taken to support some older sociological studies of gender and friendship, which maintained that men are less likely than women to form intimate relationships outside the family or to desire confiding and emotionally supportive friendships (Spencer and Pahl, 2006). It also could be argued to connect to Doucet's thesis, outlined above, that the social isolation of some fathers can be explained primarily by an unwillingness or inability to make parenting-centred friendships that is rooted in hegemonic masculinity.

While it seems plausible such inhibitions did play a role in some of the fathers' experience, further analysis of our data suggests other factors may have been of greater importance. 
Beneath the veneer of comments about introversion and unsociability were others that indicated that many fathers would have valued social contact with other parents and/or had made attempts to initiate such contact. Timothy, for example, explained that he did not mix with other adults on the days when he cares for his son because of his dislike of socialising. Later on, however, he emphasised his enjoyment of socialising at the weekend, when he and his partner spent time with friends she had made while on maternity leave. He also described how he had attempted to join a baby group but had felt that he was not accepted by the mothers there. Similarly, Scott initially attributed his lack of engagement with organised groups to his unsociability, but then went on to talk about the envy he felt at the dense networks of mothers he had observed. He also described considerable efforts he went to on his days in sole charge of his children to find some sort of company - driving significant distances across the large city in which he lived in order to meet family members. Moreover, some fathers spoke about the social isolation they sometimes felt when at home with their child. Chris, for example, who had explained his lack of social interaction on the grounds that he was 'something of an introvert' and happy on his own, later went on to acknowledge that he did not always view his circumstances so positively:

the significant majority of the other parents who are arranging play dates for children of a similar age to my daughter are women. So ... I have experienced, I don't mean deliberate but I've experienced a certain amount of isolation. (Chris - parental leave)

These contradictions in the fathers' narratives suggest their practices are unlikely to be explained entirely by a positive decision to spend time alone with their child or pre-existing inhibitions about social contact with others. In the sections below, we suggest that a range of other social factors are also likely to have affected their practices. These include an absence 
of some of the pressures mothers may feel to socialise with other parents, but particularly relate, we suggest, to some specific gender-related barriers.

\section{Differing needs and pressures}

It is likely that at least some of the reported differences between the fathers and their female partners can be explained by, firstly, the particular needs of women on maternity leave and, secondly, the pressures often experienced by mothers - but less commonly fathers - to engage in 'intensive parenting' (Hays, 1998). In the first few weeks and months after a baby's birth, interaction with other parents going through similar experiences can be a very important source of support (Mulcahy et al., 2010). In our sample, it was primarily the mothers who had assumed the role of primary caregiver in this early phase of the child's life. It is thus perhaps unsurprising that the bonds they formed with other parents (mothers) were closer and stronger than those forged subsequently by their partners. They may have had a greater need of support at this particular point - because of the challenges of taking on a new role as parent - than in later stages of parenthood. Most of the fathers had not taken extended parental leave; the majority had assumed their role as primary or equal caregiver only after their partner had completed a significant period of maternity leave. Having already become accustomed to parenthood, they may have had less urgent need for support than their partners had done immediately after their child's birth.

In addition, women may experience pressure to become involved in organised baby- or toddler-related groups or activities because they feel a strong expectation that this is a socially prescribed aspect of 'good mothering'. Brian alludes to this, in relation to his partner's experience of maternity leave, below: 
you could also equally say there is perhaps a sense of obligation that comes with that time off [maternity leave], a sense in which, well... what's the point in me being off if I'm not putting things in place... and structures and networks in place for the benefit of my child ... And sometimes that's a sort of probably an unnecessary pressure... but I think it is there and probably unavoidable. So I think... there is an awful lot of well-intentioned emphasis during pregnancy on the need to find other mums with, who you know have children of a similar age... (Brian - equal caregiver)

This 'obligation' on his partner to embed their child in stimulating social networks and activities relates closely, we would suggest, to the prescriptions of 'intensive mothering'. This is a highly demanding, child-centred approach to childrearing that involves considerable maternal investment, and which is commonly positioned not just as one of several possible approaches to parenting, but the moral choice, the way one ought to parent (Hays, 1998). It includes a pressure to attend various activities and organised groups - to develop specific skills and interests (such as in music and sport), as well as boosting intelligence through stimulating new experiences (Thomson et al., 2011). Research in the UK has suggested that fathers may be less likely to adopt such 'intensive' approaches in their parenting. Shirani et al. (2012) argue that the fathers in their study were more insulated from the demands of intensive parenting than their female partners, and typically emphasised the importance of autonomous decision-making rather than following expert advice. Thus, fathers may experience a less acute obligation to seek out and attend such organised activities. Nevertheless, while these differing needs and pressures may be significant, what came through even more strongly in our data (perhaps because we interviewed fathers and not mothers) was that most of the men we spoke to had experienced specific barriers that they felt 
had dissuaded them from participating in daytime parental spaces. These are discussed in the subsequent section.

\section{Barriers experienced by fathers}

Feeling 'out-of-place' in parenting-related daytime spaces

There is a large literature on the ways in which, historically, women have been excluded from public space. Indeed, women who have conspicuously occupied streets or other public arenas have often been seen as unnatural or unsexed (McDowell and Sharp, 1997), and continue to experience harassment and other forms of abuse in such places (Bastomski and Smith, 2017). Nevertheless, despite the significant evidence of the enduring masculine nature of much public space, many of the fathers in our sample articulated clear feelings of being 'out-ofplace' that they experienced within some daytime public spaces. These included the venues of organised activities such as baby groups and/or broader public spaces such as parks and shopping centres, where they invariably found themselves in the position of being the only visible man with young children. In relation to the former, Stephen described being the only father at child-focussed activities and groups as 'demoralising', and specifically recounted the difficulty of joining in conversations:

I know most of them [mothers in the group] but it is very much a three line conversation...you don't go much beyond that, whereas they can talk about ... 'women's problems' or whatever [problems] they had with their birth or you know all that; they're not going to have that conversation with me. (Stephen - equal caregiver) 
To some extent this difficulty was exacerbated by the long-standing nature of many such groups. As noted above, many groups are founded when women are on maternity leave. Entering such well-established groups at a later point can be difficult for men, as Patrick and Kevin explained:

And I do, you know, the mums tend to know each other a little bit more from all the... antenatal groups, so they all continue moving through together and all stuff like that and... whereas I'm sort of maybe a bit more of an outsider. (Patrick - primary caregiver)

In the first three or four months I tried quite hard to meet a few other people through baby groups and bits and pieces. But .... a lot of mums tend to be in groups already. (Kevin - primary caregiver)

This sense of being 'out-of-place' was reinforced by the names of some of the organised groups, which were taken by some to suggest they were not for fathers at all. Jeremy, for example, explained that he felt unable to go to any group with 'mummy' or 'mother' in the title, noting that while 'quite often those things will have, "Oh but everybody's welcome" ... it's like, well you've called it something that's ... not inclusive of me'. Meanwhile, in relation to public spaces more generally, fathers such as Brian and Michael explained that being the only father within environments dominated by women and children had prompted intense feelings of self-consciousness when out and about with their child.

It is important to recognise, of course, that the fathers in our sample may not be alone in feeling marginalised within daytime parenting spaces. Studies suggest that mothers too 
sometimes can feel awkward or marginalised within such spaces (Thomson et al, 2011), particularly those from working class or minority groups (Mulcahy et al., 2010). Nevertheless, the narratives of these fathers indicate their difficulties related specifically to their gendered status as men 'out-of-place'. As such, our research suggests that some public daytime spaces can be experienced as gendered and that men can sometimes feel, as Doucet puts it, like 'a threat to estrogen-filled worlds"' (2006b, p.74). On weekdays, places such as shopping centres, schools, parks, swimming pools and playgroups are often highly femaledominated, while the topics of conversation favoured by mothers of small children are not necessarily ones fathers feel comfortable with (Medved, 2016; Merla, 2008). Given that friendship is typically understood as a relationship based on perceptions of similarity (Spencer and Pahl, 2006), it may be unsurprising that - given the way in which many fathers felt so out-of-place within these spaces - relationships with other parents were hard to establish.

\section{Fear of being judged}

The potentially isolating impact of this sense of being 'out-of-place' was exacerbated, in many cases, by specific feelings of being judged, which were sometimes based on awkward previous experiences. Specifically, the fathers spoke about gendered judgements about their not being in full-time employment, their level of competence at caring for their children, and/or their motivations for wanting to be a primary or equal caregiver. The following quotations are illustrative:

People react differently because you're a dad doing things. Even things as simple as you're in a shop, you know, you're doing the shopping ...And the amount of weird 
looks you get you know if you're, because you're the dad doing this thing... it's like why is there a dad doing things on a Fri ... not in work on a Friday type things. (Andrew - equal caregiver)

...the very minority of men have done some horrible stuff and I think people are worried that it's going to happen to their child, and if they see a man with a child, I think, or a man in a setting where there are a lot of children, I think sometimes you feel a bit ... sometimes I feel that on me. (Michael - primary caregiver)

Brian was explicit about how his perception of such judgements encouraged him to avoid public space and stay at home with his daughter:

...society, no matter how much things change, still has a kind of in-built assumption that ... a mother has a natural instinct for [childcare] and a dad doesn't ... I don't think it's necessarily that I think people would be harshly judging, just that they would be observing, possibly even pitying in some respects ... that's almost worse if somebody ... the poor sod, he can't, you know, oh look mum's left him with the kid for the day and he doesn't know how to push the buggy round, you know, the wheels keep locking up. And I don't want that almost as much as being harshly judged, I'd rather just not be judged at all, I'd rather it goes back to the, if I'm in my home environment ... I really don't give a damn because it's my world. (Brian - equal caregiver)

All of the judgements described by the fathers centre on the notion of their deviation from traditional understandings of masculinity. Extending existing work then (Doucet and Merla, 
2007; Medved, 2016; Merla, 2008), our study indicates an important role for fathers' feelings of being judged and gazed at with suspicion within public spaces. Indeed, there is evidence here to support Shirani et al.'s (2012) contention that there continues to be a strong, if often implicit, gendered morality around parenting.

\section{Difficulty of meeting other caregiving fathers}

Finally, many respondents commented on the difficulty of finding other care-giving fathers to socialise with during the day. 'Dads' groups' were rarely considered to be an effective solution to respondents' difficulties with female-dominated spaces because, in their experience, such groups tended to be oriented to breadwinner fathers. In contrast to some previous studies that emphasise the need for traditionally masculine company as a form of gender compensation for involved fathers (Doucet 2004; 2006), several of our respondents felt reluctant to attend dads' groups precisely because of the traditional male identities they were believed to represent. Robert, for example, was deterred from going along to his local dads' group because of his belief that the conversation would focus only on football, and his 'unconventional' masculinity, centred on bringing up his children, would not be welcome. Timothy, meanwhile, described two dads' groups in his local area which may have provided a valuable point of contact for 'breadwinner dads' but did little to bring together dads who sought contact during weekdays while caring for their children:

I contacted the local childcare centre to find out if there were any dads' groups for contact with other fathers as it were, and unfortunately they only have two... dads' meetings a week, one of which was a Tuesday, and that's in the local pub at half past five in the evening.... which is for the dads... when they've got home from work and 
they've had half an hour with their kids and they want to get out the house, they can go to the dads' group... The other dads' meeting was on a Saturday afternoon ... and it's a chance for dads to take their kids along to give the mothers a break. (Timothy primary caregiver)

The perceived hegemonic orientation of some fathers groups, then, had made them seem unsuitable for the particular needs of some caregiving fathers. Like the Belgian stay-at-home dads examined by Merla (2008) a decade ago, some of the fathers in our study found themselves caught between female-dominated daytime parenting spaces on the one hand and masculine or breadwinner-oriented dads' groups on the other. For different reasons, neither were ideally suited to their needs and both had the potential to make them feel out-of-place.

\section{Discussion}

The extent of the lack of engagement with parent networks across our UK sample of fathers suggests that, some years after its exploration in earlier work, it may remain a significant issue. Indeed, whereas, in Doucet's research (2006a), over a quarter of fathers had been successful in establishing parent networks, in ours, the degree of apparent non-engagement with parent networks was similar across most of the sample. Doucet's main examples of successfully networked fathers, however, were fathers of older children - who had become involved in school associations or sports activities. This may underline early years parenting as an especially isolating period for fathers caring alone during the week. It is also noteworthy that the experiences of our fathers were similar irrespective of whether they were primary or equal caregivers, even if the overall impact has the potential to be greater for the latter. Meanwhile, whereas Doucet argued, in 2006, that men were gradually becoming more 
accepted in parental groups and finding it easier to establish friendships with mothers, our sample provided little evidence of this.

As well as affecting the extent to which they were taking on parental 'community responsibility' (Doucet 2006a) in the way mothers often do, the apparent social isolation of the fathers in our study from parent networks during the days they had sole charge of their children, raises questions about their well-being. While most reported being broadly content with their care-giving arrangements, some recognised possible negative consequences to spending so much time alone with their child. For example, Jason commented 'I wish I didn't do as much of it on my own, so I do try and make myself go out' - largely for the benefit of his daughter, while Kevin explained that he was keen for his daughter to attend some sessions at the local nursery so that she had the opportunity to interact with other children. However, while most of these concerns were framed in relation to children's well-being, it is likely that fathers themselves may also suffer from prolonged periods of social isolation, particularly in the case of those spending substantial proportions of the week in sole charge of their children. Such isolation was discussed explicitly by some of our respondents, including Chris whom we cited above. While some previous research has noted that fathers, parenting alone, can feel isolated and lonely (Brandth and Kvande, 2018), other studies have emphasised, instead, associations between the primary care of an infant and subjective happiness (O'Brien et al., 2017). Our research is thus significant in highlighting that - alongside many positive benefits to fathers and their families - primary or equal paternal care still has the potential to be associated with particular forms of isolation.

The reasons for the fathers' comparative lack of engagement with parent networks were complex. We outlined how our respondents tended initially to explain that they were 
unsociable and/or introverted but that such explanations appeared not to tell the full story. This initial recourse to individualistic explanations, we argue, can be seen as an example of what Furlong and Cartmel (2007) have called the 'epistemological fallacy': the impact of social structures, such as class and gender becomes 'increasingly obscure as collectivist traditions weaken and individualist values intensify' (p.2-3). People, then, come to understand the world as negotiable primarily on individualised terms. Such explanations may also in some cases be understood as 'face saving' strategies, however. Playing down one's desire for social connection may be preferable to a discourse centred on social endeavours that might be construed as unsuccessful. It remains possible that, collectively, fathers' drive for parental company may be less acute than, for example, that of mothers in the initial postpartum period. They may also feel less pressure than mothers when it comes to intensive parenting and associated drives to facilitate their children's participation in public activities. And we acknowledge the importance of Doucet's (2006a) argument that masculine approaches to friendships may sometimes prompt fathers to feel a need to be autonomous, avoiding intimacy with other men, while 'equally wary of the danger of closeness with women' (p.154) because such friendships could be viewed by suspicion by others (also see O’Brien and Twamley, 2017).

What was particularly highlighted by the research, however, was the ways the fathers felt excluded from parent networks and marginalised within daytime spaces as a result of their status as caregiving fathers. The fathers' awareness of how their care-giving activities jarred with hegemonic masculinity and how this could lead to awkwardness or marginalisation within daytime parenting spaces pervaded this discussion. Many respondents avoided baby groups and other organised activities - and, sometimes, engaging in public space more generally - because of feeling out-of-place and/or judged on the basis of their status as 
fathers within maternal environments and their transgressions of traditional notions of masculinity. In addition, maternity leave (and also ante- and post-natal groups attended by women) had, in many cases, facilitated the construction of close networks of mothers, which were hard for fathers to engage with at the later point at which they 'took over' some or most daily care-giving from their partner. Most of our fathers had taken on a primary or equal caring role several months after their child had been born, once social networks amongst mothers of similar-aged children were already well-established. Moreover, the reluctance of some to participate in what they regarded as traditional, breadwinner-oriented dads' groups also reflected concerns about their positioning vis-à-vis hegemonic masculinity. Though it could have played some role, then, in most cases their avoidance of such groups did not seem primarily to reflect a fear of establishing an emotional connection with other men or an awkwardness discussing their role as parents with other fathers. Many would have welcomed male contact with other primary or equal caregivers that centred on their non-traditional nurturing role, but felt this was not available.

Of importance here are the ways this evidence articulates with broader debates about the intersections of gender and public space. As noted previously, there is a substantial literature that documents how women have been excluded from public space by, for example, the ways in which towns and cities have been planned, the association between public space and employment, and fear of sexual harassment and other types of uncivil behaviour (e.g. Bastomski and Smith, 2017). Nevertheless, our data demonstrate that the relationship between gender and public space is complex, and that, in some circumstances, men can experience spatial exclusion. Many of the fathers whom we interviewed spoke of their unease at being 'out and about' when caring for their child or children in spaces they experienced as female-dominated. The fathers' descriptions of these spaces reflect what Boterman and 
Bridge (2014) observed in their comparative study of parenting spaces in London and Amsterdam. In relation to the former, they note that 'certain neighbourhood spaces are strongly feminised and associated with young motherhood in highly visible ways' (p.257). Similarly, Dworkin notes that involved fathers in her study were wary of "worlds populated mainly by mothers and mothering networks which sometimes cast suspicious scrutiny on male participants' (2006b, p.704). Moreover, the narratives of the fathers suggest a temporal dimension to such processes of exclusion: it was typically during the working day that they felt 'out-of-place' in certain public spaces - particularly those associated with leisure and parenting. McDowell (1999) has argued that a specific space may, over the course of a particular period of time (potentially as short as a day), 'be occupied by a series of social groups whose practices imbue the same spaces with different meanings at different times' (p.168). On the basis of our data, we do not, of course, claim that fathers are excluded as a matter of course from daytime public space; rather, that within particular parenting-centred spaces during the working day, men caring alone for young children can sometimes feel outof-place.

The reasons provided by the fathers for feeling this way were based, as we have documented above, on their sense of difference from the women who frequented many of the baby groups and leisure spaces they had visited, but also the comments made by others about their 'out-ofplace' position, and their own fears (even if never realised) that they would be seen in this way. Here, in the unusual context of a sample of fathers caring for young children during the day, we can see an example of the operation of gender in particular spaces and times that seems to complicate - at least a little - the traditional binary association of masculinity with public space and femininity with private space. In this respect, we build on existing work that highlights nuances and changes in the gendering of space (Spain, 2014). Thus, while in many 
spaces and times, it remains difficult for women to occupy public space with the same ease as men, the case of fathers who have taken on the traditionally feminine role of caregiver provided an example where this had become turned-around somewhat - albeit in specific spaces (such as parents' groups, shops, parks and swimming pools) and at specific times (during the working day).

Such patterns clearly relate to enduring norms about gender roles and, in particular, expectations - and perceived expectations - that men will typically be at work during the day, rather than present in leisure-related public spaces. Evidence from other countries suggests that where such expectations are brought into question - for example, through policies that incentivise the uptake of paternal leave and/or encourage more egalitarian parenting practices - men's experiences are rather different. Indeed, Boterman and Bridge (2014) have argued that, in Amsterdam, where it is almost as common to see children being looked after on weekdays by their fathers as their mothers, highly feminised social spaces such as cafes are much less common that in London. Similarly, in her study of parenting practices in Helsinki, Lilius (2017) reports that 'latte dads' (i.e. fathers who spend time in coffee shops, when looking after their children) are as common a phenomenon as 'latte mums', and that there is no great difference in the spatiality of mothering and fathering.

Presence and visibility within such spaces is also important for bringing about social change. As Evans (2016) has argued, public 'exposure' of non-traditional patterns is important in affecting change to dominant practices. More specifically, she contends that flexibility in the gender division of labour has tended to foster, rather than follow, changes in gender ideologies. In our research, the relative invisibility of our respondents within parenting networks and spaces may suggest that the significant challenges their practices were making 
to traditional divisions of labour may have had less effect in changing the attitudes and practices of others than if they felt more comfortable in public spaces and integrated in parent networks. Clearly, however, there are important interdependencies here; a key reason why the fathers tended to avoid such 'exposure' was, at least in part, precisely because of what they perceived to be the traditional and judgemental attitudes of others.

\section{Conclusion}

This article has drawn on interviews with 24 fathers who have assumed primary or equal responsibility for the care of their children to explore their social interactions. We have shown how, in spite of usually feeling positive overall about their experiences, many of the men in the sample had relatively little contact with other parents during the time they were caring for their child/children alone. Although many explained their preference for spending time alone with their child in terms of their own 'introverted' or 'unsociable' nature, we have suggested such individualised initial narratives underplay the ways in which systemic barriers were constraining their interactions. We have argued that such barriers connect to a sense of feeling 'out-of-place' and a fear of being judged in relation to their gender within feminised public spaces - alongside the difficulty of meeting other fathers with responsibility for dayto-day care. Such barriers, we contend, suggest that, even in cases where fathers take on caregiving roles that challenge traditional roles, substantial gender barriers continue to persist with respect to their integration within parenting communities and public space. As well as illustrating the enduring gender-segregation of men's and women's friendships in this sphere, this - could have implications for fathers' well-being and for the extent and longevity of their roles as caregiving fathers. Furthermore, through rendering their care-sharing as relatively 'invisible', their limited engagement with public parenting spaces may lessen the 
effectiveness of their progressive activities in contributing to the broader undoing of gender ideologies than if fathers were fully integrated into parenting networks.

\section{Funding}

This work was supported by a grant from the Faculty of Arts and Social Sciences at the University of Surrey.

\section{Conflict of interest}

The Authors declare there is no conflict of interest.

\section{Acknowledgements}

We are grateful to the Faculty of Arts and Social Sciences at the University of Surrey for funding the empirical work upon which we draw in this article.

\section{References}

Banister, E. and Kerrane, B. (2018) New Generation of Working Parents Demand a Better

Deal of Parental Leave, The Conversation, URL: https://theconversation.com/newgeneration-of-working-parents-demand-a-better-deal-on-shared-parental-leave-102993

Bastomski, S. and Smith, P. (2017) 'Gender, Fear, and Public Places: How Negative Encounters with Strangers Harm Women', Sex Roles, 76: 73-88 
Brandth, B. and Kvande, E. (2018) 'Masculinity and Fathering Alone during Parental Leave', Men and Masculinities, 2(1): 72-90.

Boterman, W. and Bridge, G. (2014) 'Gender, class and space in the field of parenthood: middle-class fractions in Amsterdam and London', Transactions of the Institute of British Geographers, 40: 249-261.

Chelsey, N. (2011) 'Stay at Home Fathers and Breadwinning Mothers', Gender and Society, 25(5): 642-664.

Dermott, E. (2009) Intimate Fatherhood. A sociological analysis, London: Routledge.

Doucet, A. (2004) “'It's almost like I have a job but I don't get paid”: Fathers at home reconfiguring work, care and masculinity', Fathering 2(3): 277-303.

Doucet, A. (2006a) Do Men Mother?, Toronto: University of Toronto Press.

Doucet, A. (2006b) “"Estrogen-filled worlds”: fathers as primary caregivers and embodiment', The Sociological Review, 54(4): 696-716.

Doucet, A. and Merla, L. (2007) 'Stay-at-home Fathering: A Strategy for Balancing Work and Home in Canadian and Belgian Families', Community, Work and Families 10: 455-73. 
Evans, A. (2016) 'The Decline of the Male Breadwinner and Persistence of the Female Carer', Annals of the American Association of Geographers, 106(5): 1135-1151.

Furlong, A. and Cartmel, F. (2007) Young People and Social Change, Maidenhead: Open University Press.

Hays, S. (1998) The Cultural Contradictions of Motherhood, New Haven: Yale University Press.

Lilius, J. (2017) 'Urban space in the everyday lives of mothers and fathers on family leave in Helsinki', European Urban and Regional Studies, 24(1): 104-118.

McDowell, L. and Sharp, J. (eds) (1997) Space, Gender, Knowledge. Feminist Readings, London: Arnold.

McDowell, L. (1999) Gender, Identity and Place, Cambridge: Polity Press.

Merla, L. (2008) 'Determinants, Costs and Meanings of Belgian Stay-At-Home Fathers: an International Comparison', Fathering, 6(2): 113-32.

Medved, C. (2006) ‘Fathering, caregiving, masculinity’, in K. Floyd and M. Moron (eds.) Widening the Family Circle, New York, Sage. pp.115-132.

Miller, T. (2005) Making Sense of Motherhood, Cambridge: Cambridge University Press. 
Miller, T. (2011) Making Sense of Fatherhood. Gender, caring and work, Cambridge:

Cambridge University Press.

Mulcahy, C., Parry, D. and Glover, T. (2010) 'Play-group politics: a critical social capital exploration of exclusion and conformity in mothers groups', Leisure Studies, 29(1): 3-27.

Norman, H., Elliot, M. and Fagan, C. (2018) Does Fathers' Involvement in Childcare and Housework Affect Couples’ Relationships Stability? Social Science Quarterly 9advance online access).

O’Brien, M., Connolly, S., Speight, S., Aldrich, M. and Poole, E. (2016) 'The United Kingdom', in M. Adler and K. Lenz (eds) Father Involvement in the Early Years. An international comparison of policy and practice, Bristol, The Policy Press. pp.157-192

O'Brien M. and Twamley K. (2017) 'Fathers Taking Leave Alone in the UK - A Gift Exchange Between Mother and Father?', in M. O'Brien and K. Wall (eds) Comparative Perspectives on Work-Life Balance and Gender Equality, Springer, Cham. pp.163-182.

Parke, R. (2013) Future Families: Diverse Forms, Rich Possibilities, Oxford: Wiley Blackwell.

Ranson, G. (2010) Against the Grain. Couples, Gender and the Reframing of Parenting, Toronto: University of Toronto Press. 
Shirani, F., Henwood, K. and Coltart, C. (2012) 'Meeting the challenge of intensive parenting culture: gender, risk management and the moral parent', Sociology, 46(1): 25-40.

Soloman, C. (2017) The Lives of Stay-At-Home Fathers, Bingley: Emerald.

Spain, D. (2014) 'Gender and urban space', Annual Review of Sociology, 40: 581-98.

Spencer, L. and Pahl, R. (2006) Rethinking Friendship, Princeton: Princeton University Press.

Thomson, R., Kehily, M.J., Hadfield, L. and Sharpe, S. (2011) Making Modern Mothers, Bristol: Policy Press. 